\title{
Validation of Quetiapine Fumarate in Pharmaceutical Dosage by Reverse-Phase HPLC with Internal Standard Method
}

\author{
Kiran B. Venkata, Sreenivas Rao Battula, and Somshankar Dubey \\ Department of Chemistry, GITAM Institute of Technology, GITAM University, Andhra Pradesh, Visakhapatnam 530045, India \\ Correspondence should be addressed to Sreenivas Rao Battula; battula_sr@gitam.edu
}

Received 9 December 2011; Revised 8 May 2012; Accepted 21 May 2012

Academic Editor: Daryoush Afzali

Copyright (C) 2013 Kiran B. Venkata et al. This is an open access article distributed under the Creative Commons Attribution License, which permits unrestricted use, distribution, and reproduction in any medium, provided the original work is properly cited.

\begin{abstract}
A rapid, specific, and accurate isocratic HPLC method was developed and validated for the assay of quetiapine fumarate in pharmaceutical dosage forms. The assay involved an isocratic-elution of quetiapine fumarate in Grace C18 column using mobilephase composition of $0.1 \%$ ortho phosphoric acid with triethyl amine as modifier buffer and acetonitrile in the ratio of $50: 50$ $(\mathrm{v} / \mathrm{v})$. The wavelength of detection is $294 \mathrm{~nm}$. The method showed good linearity in the range of $2.0-50.2 \times 10^{-3} \mathrm{~g} / \mathrm{Lt}$. The runtime of the method is 5 mins. The developed method was applied to directly and easily analyse of the pharmaceutical tablet preparations. The percentage recoveries were near $100 \%$ for given methods. The method was completely validated and proven to be rugged. The excipients did not interfere in the analysis. The results showed that this method can be used for rapid determination of quetiapine fumarate in pharmaceutical tablet with precision, accuracy, and specificity.
\end{abstract}

\section{Introduction}

Quetiapine fumarate (Figure 1) - chemically known as $\{2$ (2-(4-dibenzo [1, 4] thiazepine-11-yl-1-piperazinyl) ethoxyethanol, fumaric acid (1:2 salt; formula $\mathrm{C}_{29} \mathrm{H}_{33} \mathrm{~N}_{3} \mathrm{O}_{10} \mathrm{~S}$ ), molecular weight: 615.66-a dibenzothiazepine derivative, is one of the most recent antipsychotic drugs. An oral antipsychotic drug that acts as an antagonist of multiple neurotransmitters including serotonin and norepinephrine is used in the treatment of schizophrenia. It is a selective monoaminergic antagonist with high affity for the serotonin type $2\left(5 \mathrm{HT}_{2}\right)$ and dopamine type $2\left(\mathrm{D}_{2}\right)$ receptors. QTF belongs to the same family as clozapine and olanzapine, which are classified as a typical antipsychotic and do not cause major extrapyramidal side effects. The generic name of quetiapine hemifumarate is Seroquel; it is prescribed for the treatment of schizophrenia, a mental disorder marked by delusions (false beliefs), hallucinations, disrupted thinking, and loss of contact with reality. It is also used for the shortterm treatment of mania associated with bipolar disorder. Seroquel is the first in a new class of antipsychotic medications. Researchers believe that it works by diminishing the action of dopamine and serotonin, two of the brain's chief chemical messengers. It is white or almost white powder, moderately soluble in water and soluble in methanol and $0.1 \mathrm{~N} \mathrm{HCl}$. It is available in tablets form in dosage level of $25 \mathrm{mg}, 50 \mathrm{mg}, 100 \mathrm{mg}, 200 \mathrm{mg}, 300 \mathrm{mg}$, and $400 \mathrm{mg}$. Maximum daily dosage is $800 \mathrm{mg}$ in adults. This drug is rapidly absorbed after oral administration with peak plasma concentration attained within $1.50 \mathrm{hrs}$. Bioavailability of tablet formulation is $100 \%$ relative to an oral solution, which may be marginally affected by food. Plasma protein binding of quetiapine is $83 \%$. The drug is extensively metabolites, principally through CYP3A4. The drug is having half-life period of approximately 6 hours.

Several methods have been reported for the quantitative determination of quetiapine in bulk, and pharmaceutical and biological samples. These methods include UV-Visible spectrophotometric [1-3], UV-derivative and extraction-free methods [4], HPTLC [5], Capillary zone electrophoretic method [6], HPLC-UV-detector [7-11], HPLC with solidphase extraction [12], UPLC with mass-spectrophotometer detector [13], HPLC with column switching method [14], gas-chromatography-liquid chromatography-mass spectrophotometry [15], and hyphenated techniques such as LC-MS [16], HPLC-electrospray mass ionization mass spectrometry 
<smiles>O=C(O)/C=C/C(=O)O</smiles>

FIGURE 1: Quetiapine fumarate.

[17], HPLC-Tandem-mass spectropmetry [18], and HPLCMS-MS method [19].

Literature survey revealed that only few internal standard methods have been reported for the quantification of quetiapine fumarate in bulk and pharmaceutical formulations. A comparison of various methods with present study has been tabulated in (Table 11). So, the authors have developed a new internal standard method which is more rugged, precise, and accurate.

\section{Experimental}

2.1. Chemicals and Reagents. Quetiapine fumarate (99.92\%) was gift sample from corpuscle research solutions and lamotrogine (99.89\% pure, internal standard was procured from corpuscle research solutions. Ascetonitrile (HPLC grade) was obtained from Qualigens fine chemicals. Milli-Q water was purchased from Ranbaxy fine chemicals limited (RFCL). All chemicals used were of analytical grade.

2.2. Instrumentation. The HPLC system consisted of a Shimadzu Class VP Binary pump LC-10Atvp, SIL-10Dvp Autosampler, CTO-10Avp column temperature Oven, PDAUV Detector. All the components of the system are controlled using SCL-10Avp System Controller. Data acquisitions were done using LC-solution software. The mobile phase consists of $50: 50(\mathrm{v} / \mathrm{v})$ of acetonitrile and $0.1 \%$ orthophosphoric acid with added tri-ethyl amine as modifier, operated on isocratic mode. Analysis was carried out at $294 \mathrm{~nm}$. The chromatographic separation of quetiapine fumarate (drug) and lamotrogine (ISTD) was carried out using GRACE Genesis C18 column $(50 \times 4.6 \mathrm{~mm} \mathrm{ID}, 3 \mu \mathrm{m})$. The flow rate is $0.6 \mathrm{~mL} / \mathrm{min}$. The injection volume is $10 \mu \mathrm{L}$. Diluents consists of $50: 50(\mathrm{v} / \mathrm{v})$ methanol and $0.1 \%$ orthophosphoric acid.

\subsection{Preparation of Solutions}

2.3.1. Drug Stock Solution and Internal Standard. Two different stock solutions of quetiapine fumarate working standard and lamotrogine (internal standard) were prepared by dissolving accurately weighed $10 \mathrm{mg}$ of drug in $10 \mathrm{~mL}$ of acetonitrile, so that final concentration is $1 \mathrm{mg} / 1 \mathrm{~mL}$. The prepared stock solution is stored in $4^{\circ} \mathrm{C}$ protected from light. Suitable dilutions of drug and internal standard were prepared by using $50: 50 \mathrm{v} / \mathrm{v}$ methanol and $0.1 \%$ orthophosphoric acid as diluents solution. Dilution of internal standard is prepared to obtain a final concentration of $600 \times 10^{-3} \mathrm{~g} / \mathrm{Lt}$.

2.3.2. Calibration Standards and Quality Control Samples. An eight point linear calibration curve standards were prepared using diluents solutions in the concentration range of 2.01 to $50.20 \mathrm{~g} / \mathrm{Lt}$. Calibration standards were prepared at the concentration of $(2.008,5.120,10.040,15.060,25.100$, 40. $160,45.180,50.200) \times 10^{-3} \mathrm{~g} / \mathrm{Lt}$ from first standard stock solution. $950 \times 10^{-6} \mathrm{~L}$ of the linear calibration standard and $50 \times 10^{-6} \mathrm{~L}$ of internal standard dilution were transferred into the autosampler for analysis. Three quality control samples were at the concentrations of $5.120 \times 10^{-3} \mathrm{~g} / \mathrm{Lt}, 15.060 \times$ $10^{-3} \mathrm{~g} / \mathrm{Lt}$, and $40.160 \times 10^{-3} \mathrm{~g} / \mathrm{Lt}$ representing low-medium and high concentration, respectively.

2.3.3. Sample Preparation. Commercially available tablets of quetiapine fumarate are taken from two different brands and tested for assay. Twenty tablets of each brand are taken and crushed to powder. A powder equivalent to $50 \times 10^{-3} \mathrm{~g}$ of quetiapine fumarate is taken and transferred into a stoppered conical flask to which $25 \mathrm{~mL}$ of methanol is added. The contents are transferred into a stoppered flask and shaken for 20 mins to extract the drug. Contents are carefully transferred into a centrifuge tube and centrifuged for $4000 \mathrm{rpm}$ for 20 mins. The supernatant liquid is taken and diluted with diluents, to obtain approximately final concentration of $25 \times$ $10^{-3} \mathrm{~g} / \mathrm{Lt}$. This sample is analyzed in triplicate. The accuracy and concentration are determined using regression equation.

\subsection{Method Validation}

2.4.1. System Suitability. System suitability is an integral part of the LC method. They are used to verify that resolution. Reproducibility is adequate. This is based on the concept that equipment, electronics, analytical operations, analytical operator, and sample constitute an integral system that can be evaluated as such. The system suitability was assessed by six replicate analysis of the drug at a concentration of $15.06 \times 10^{-3} \mathrm{~g} / \mathrm{Lt}$. The acceptance criterion is $\pm 1 \%$ for the percent coefficient of the variation for the peak area and retention times for both drug and internal standard. The parameters which we have evaluated are USP theoretical plates, USP tailing factor, and USP resolution. The following formulas have been used for the calculation of

$$
\begin{aligned}
& \text { USP resolution: Rs }=2\left(T_{1}-T_{2}\right) / W_{1}-W_{2} \\
& \text { USP theoretical plates }=5.54\left[T_{R} / W_{R}\right]^{2} \\
& \text { USP tailing }=W_{0.5} / 2 \mathrm{~d} .
\end{aligned}
$$


TABLE 1: System suitability study.

\begin{tabular}{|c|c|c|c|c|c|c|c|c|}
\hline \multicolumn{9}{|c|}{ System suitability } \\
\hline & ISTD & Drug & T.P & Tailing & Resolution & $\mathrm{P} / \mathrm{A}$ ratio & RT (ISTD) & RT (drug) \\
\hline Inj-01 & 802777 & 557601 & 5485 & 1.25 & 10.21 & 0.695 & 1.45 & 3.62 \\
\hline Inj-02 & 796543 & 564024 & 5449 & 1.25 & 10.23 & 0.708 & 1.45 & 3.63 \\
\hline Inj-03 & 788450 & 542945 & 5566 & 1.25 & 10.37 & 0.689 & 1.44 & 3.63 \\
\hline Inj-04 & 773744 & 545361 & 5619 & 1.25 & 10.43 & 0.705 & 1.44 & 3.62 \\
\hline Inj-05 & 787322 & 543398 & 5587 & 1.25 & 10.32 & 0.690 & 1.44 & 3.62 \\
\hline Inj-06 & 791033 & 551887 & 5457 & 1.25 & 10.28 & 0.698 & 1.44 & 3.62 \\
\hline Mean & 789978 & 550869 & 5527 & 1.25 & 10.3067 & 0.697334 & 1.443 & 3.623 \\
\hline S.D & 9807.74 & 8583.17 & 72.57 & 0.00 & 0.0841 & 0.00783 & 0.005 & 0.005 \\
\hline RSD & 1.24 & 1.56 & 1.31 & 0.00 & 0.8156 & 1.122889 & 0.358 & 0.143 \\
\hline
\end{tabular}

TABLE 2: Limit of detection.

\begin{tabular}{|c|c|c|c|c|c|}
\hline Injection number & Drug (area) & $\mathrm{P} / \mathrm{A}$ ratio & T.P & T.F & Resolution \\
\hline 01 & 4103 & 0.004912 & 6609 & 1.2 & 11.17 \\
\hline 02 & 4186 & 0.005062 & 6845 & 1.23 & 11.28 \\
\hline 03 & 4241 & 0.005123 & 6787 & 1.26 & 11.03 \\
\hline 04 & 4360 & 0.005227 & 6912 & 1.15 & 11.32 \\
\hline 05 & 4238 & 0.005048 & 6974 & 1.22 & 11.3 \\
\hline 06 & 4263 & 0.005132 & 6874 & 1.2 & 11.27 \\
\hline Mean & 4231.83 & 0.0051 & 6833.5 & 1.21 & 11.22833 \\
\hline S.D & 85.11 & 0.0001 & 126.6787 & 0.036878 & 0.110167 \\
\hline RSD & 2.01 & 2.0803 & 1.85379 & 3.047783 & 0.981148 \\
\hline
\end{tabular}

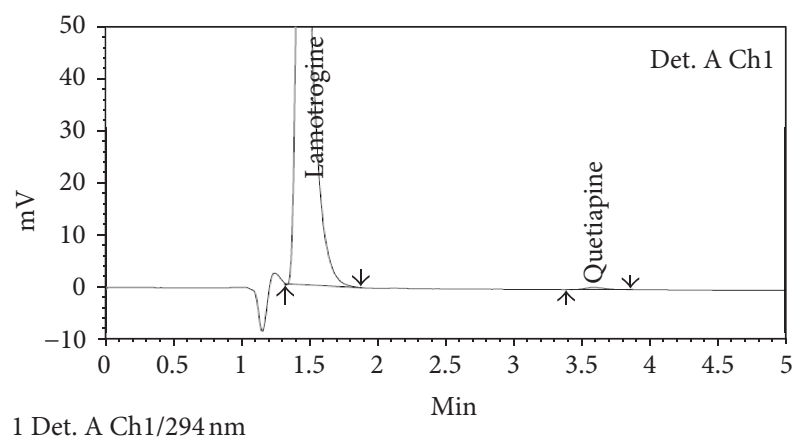

FIGURE 2: Representative chromatogram of LOD injection.

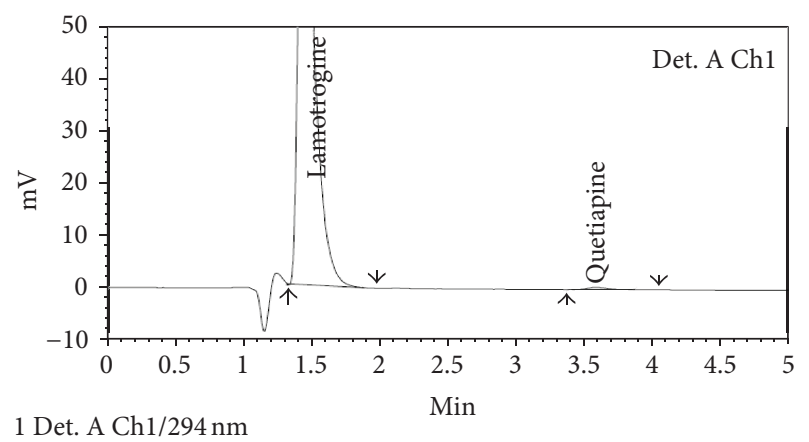

Figure 3: Representative chromatogram of LOQ injection.
2.4.2. Detection and Quantization Limits (Sensitivity). Limits of detection (LOD) (Figure 2) and quantization (LOQ) (Figure 3) were estimated from both linearity calibration curve method and signal-to-noise ratio method. The detection limit was defined as the lowest concentration level resulting in a peak area of three-times baseline noise. The quantization limit was defined as the lowest concentration level that provided a peak area with signal-to-noise ratio higher than 10, with precision $(\% \mathrm{CV})$ and accuracy with (土) $10 \%$.

2.4.3. Linearity (Calibration Curve). The calibration curves were constructed with eight concentrations ranging from
2.01 to $50.20 \mu \mathrm{g} / \mathrm{mL}$. The peak area ratio of the drug to the internal standard was evaluated by linearity graph. The linearity was evaluated by linear regression analysis, which was calculated by least square method. It is depicted in (Figure 4).

2.4.4. Accuracy and Precision. Accuracy of assay method was determined for both intraday and interday variations using triplicate analysis of the QC samples. Precision of the assay was determined by repeatability (intra-day) and intermediate precision (interday). Repeatability refers to the use of the analytical procedure within the laboratory over the shorter period of the time that was evaluated by assaying the QC 
TABLE 3: Limit of quantification.

\begin{tabular}{|c|c|c|c|c|c|}
\hline Injection number & Drug (area) & $\mathrm{P} / \mathrm{A}$ ratio & T.P & T.F & Resolution \\
\hline 01 & 8421 & 0.009684 & 6395 & 1.26 & 11.06 \\
\hline 02 & 8909 & 0.010346 & 6345 & 1.37 & 11.09 \\
\hline 03 & 8790 & 0.010184 & 6388 & 1.23 & 11.06 \\
\hline 04 & 8438 & 0.009815 & 6609 & 1.32 & 11.09 \\
\hline 05 & 8220 & 0.009523 & 6506 & 1.23 & 11.08 \\
\hline 06 & 8492 & 0.009898 & 6323 & 1.23 & 11 \\
\hline Mean & 8545 & 0.009908 & 6427.667 & 1.273333 & 11.06333 \\
\hline S.D & 256.0391 & 0.000308 & 109.0388 & 0.058878 & 0.033862 \\
\hline RSD & 2.996361 & 3.112017 & 1.696398 & 4.623959 & 0.306078 \\
\hline
\end{tabular}

TABLE 4: Results and regression analysis of linearity data of quetiapine fumarate.

\begin{tabular}{lc}
\hline & Mean \pm S.D $(n=3)$ \\
\hline Slope & $25.10 \pm 0.06$ \\
Intercept & $-1.186 \pm 0.08$ \\
Correlation coefficient $\left(R^{2}\right)$ & $0.999 \pm 0.0003$ \\
\hline
\end{tabular}

Each mean value is a result of triplicate analysis $(n=3)$.

samples during the same day. Intermediate precision was assessed by comparing the assays on different days (3 days).

2.4.5. Specificity. Specificity of the method was determined by injecting 3 samples:

(1) blank sample (Figure 5),

(2) sample with internal standard and no drug (zero blank) (Figure 6),

(3) sample containing both internal standard and drug (Figure 7).

A less than $20 \%$ interference of the peak area at the retention time of the drug in the blank sample and zero blank samples are taken as acceptance criteria for the analyte. The interference of the internal standard the peak area at the retention time of the internal standard must be less than $5 \%$ in the blank sample. Specificity is also observed in the degradation study of the drug. None of the degraded products must interfere with the quantification of the drug.

2.4.6. Stability. The stability of the drug is determined by using QC samples kept at room temperature up to 12 hours and then analyzing them. Further, autosampler stability for up to $24 \mathrm{hrs}$ and long-term stability unto 30 days were also established.

2.4.7. Stress Testing. Stress testing of the drug substance can help identify the likely degradation products; we can also validate the stability and specificity of the analytical procedure. For degradation study $10 \mathrm{mg}$ of quetiapine fumarate was accurately weighed and transferred to a $10 \mathrm{~mL}$ volumetric flask (step 1). 6 sets of $1 \mathrm{~mL}$ aliquots were taken and transferred into ria vials. Set 1 is left untreated, to the sample

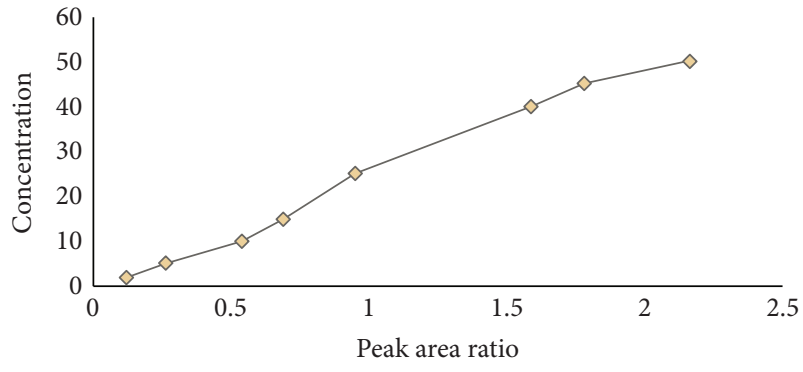

$\diamond$ Average linerity

Figure 4: Linearity data.

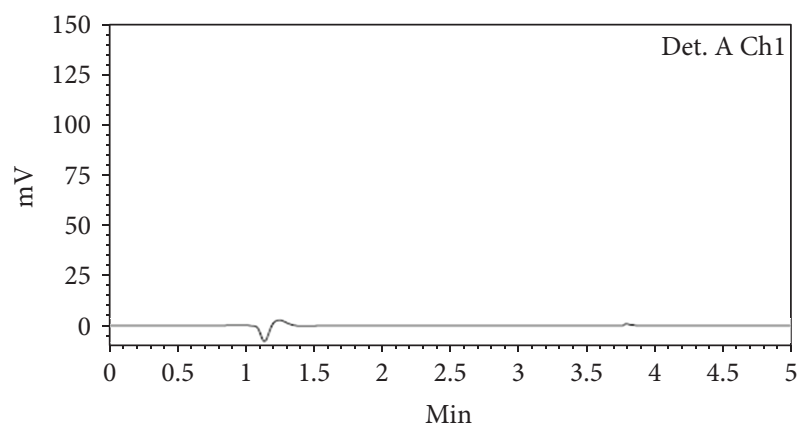

1 Det. A Ch1/294nm

Figure 5: Blank.

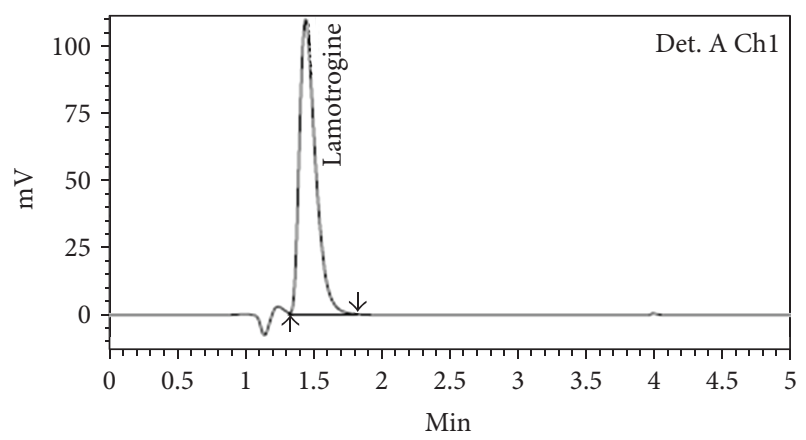

1 Det. A Ch1/294nm

FIgURE 6: Zero blank. 
TABLE 5: Intraday and interday precision and accuracy of HPLC assay of quetiapine fumarate.

\begin{tabular}{|c|c|c|c|}
\hline \multicolumn{4}{|c|}{ Nominal concentration } \\
\hline & $5.12 \times 10^{-3} \mathrm{~g} / \mathrm{Lt}$ & $15.06 \times 10^{-3} \mathrm{~g} / \mathrm{Lt}$ & $40.16 \times 10^{-3} \mathrm{~g} / \mathrm{Lt}$ \\
\hline \multicolumn{4}{|l|}{ Day 1} \\
\hline Mean $(n=3)$ & 183638 & 502614 & 1297619 \\
\hline S.D & 948.01 & 10442.68 & 1514.80 \\
\hline R.S.D & 0.52 & 2.07 & 0.12 \\
\hline Recovery (\%) & 100.4907 & 100.11 & 99.49 \\
\hline \multicolumn{4}{|l|}{ Day 2} \\
\hline Mean $(n=3)$ & 227511 & 523982 & 1310744 \\
\hline S.D & 379.36 & 3262.83 & 21904 \\
\hline R.S.D & 0.17 & 0.62 & 1.67 \\
\hline Recovery (\%) & 100.64 & 101.00 & 99.52 \\
\hline \multicolumn{4}{|l|}{ Day 3} \\
\hline Mean $(n=3)$ & 199599 & 516802 & 1293679 \\
\hline S.D & 1216.50 & 4041.45 & 1760.91 \\
\hline R.S.D & 0.61 & 0.78 & 0.14 \\
\hline Recovery (\%) & 99.36 & 101.50 & 99.69 \\
\hline
\end{tabular}

Each mean value is a result of triplicate analysis $(n=3)$.

TABLE 6: Short-term, long-term, and autosampler stability of quetiapine fumarate.

\begin{tabular}{lccc}
\hline & Nominal concentration & & \\
& $5.12 \times 10^{-3} \mathrm{~g} / \mathrm{Lt}$ & $15.06 \times 10^{-3} \mathrm{~g} / \mathrm{Lt}$ & $40.16 \times 10^{-3} \mathrm{~g} / \mathrm{Lt}$ \\
\hline Short-term stability $(12 \mathrm{hrs})$ & & & 1273781 \\
Mean $(n=3)$ & 185884 & 512701 & 2057.69 \\
S.D & 1239.619 & 2388.92 & 0.16 \\
R.S.D & 0.6669 & 0.47 & 98.52 \\
Recovery (\%) & 100.38 & 100.77 & 1281959 \\
Autosampler stability (24 hrs) & & & 6885.33 \\
Mean $(n=3)$ & 200490 & 5069977 & 0.54 \\
S.D & 813.61 & 3132.07 & 98.31 \\
R.S.D & 0.41 & 0.62 & 100.19 \\
Recovery (\%) & 100.00 & & 98.37 \\
\hline
\end{tabular}

TABLE 7: Results of quetiapine fumarate exposed to different pathways.

\begin{tabular}{lccc}
\hline & Average area & Average recovery & \% Degradation \\
\hline Oxidation & 744086 & 98.27 & 1.73 \\
Alkaline & 747898 & 98.78 & 1.22 \\
Acidic & 750779 & 99.16 & 0.14 \\
UV & 754257 & 99.62 & 0.38 \\
Thermal & 745145 & 98.41 & 1.59 \\
\hline
\end{tabular}

Each value is a result of triplicate analysis.

of set $2,100 \times 10^{-6}$ of $0.1 \mathrm{~N} \mathrm{NaOH}$, for set $3,100 \times 10^{-6} \mathrm{~L}$ of $0.1 \mathrm{~N} \mathrm{HCL}$, for set $4,100 \times 10^{-6} \mathrm{~L}$ of $3 \% \mathrm{H}_{2} \mathrm{O}_{2}$ were added; these sets of samples were placed in a water bath maintained at $60^{\circ} \mathrm{C}$ for about $24 \mathrm{hrs}$; for set 5 , sample is exposed to UV lamp at $294 \mathrm{~nm}$ for about $24 \mathrm{hrs}$; for set 6, sample is kept in a oven at temperature of about $105^{\circ} \mathrm{C}$, for about $24 \mathrm{hrs}$. All the samples are kept under stress condition for $24 \mathrm{hrs}$ before final analysis. Samples are then taken; $50 \times 10^{-6} \mathrm{~L}$ of internal

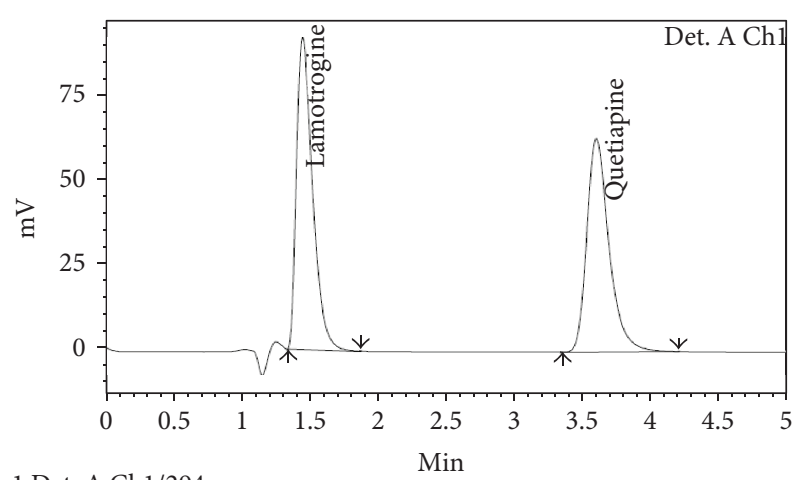

1 Det. A Ch1/294nm

FIGURE 7: Typical chromatogram containing internal standard and drug.

standard is added and diluted with diluents solution to obtain a final concentration of $25.10 \times 10^{-3} \mathrm{~g} / \mathrm{Lt}$. The comparison of drug degraded (if any) is measured against untreated sample at the same concentration. 
TABle 8: Specificity data for stress conditions.

\begin{tabular}{|c|c|c|c|c|c|c|}
\hline Stress condition & Retention time & Area & Purity 1 angle & Purity 1 threshold & USP plate count & USP tailing \\
\hline Untreated & 3.95 & 757150 & 0.07 & 0.26 & 5560 & 1.22 \\
\hline Oxidation & 3.85 & 744086 & 0.20 & 0.24 & 4499 & 1.40 \\
\hline Thermal & 3.93 & 747898 & 0.15 & 0.28 & 4300 & 1.42 \\
\hline Alkaline & 3.78 & 750779 & 0.22 & 0.24 & 4200 & 1.38 \\
\hline Acidic & 3.94 & 754257 & 0.14 & 0.25 & 4800 & 1.35 \\
\hline UV & 3.93 & 745145 & 0.19 & 0.24 & 4856 & 1.26 \\
\hline
\end{tabular}

TABLE 9: Effect of various parameters in assessment of method.

\begin{tabular}{|c|c|c|c|c|c|}
\hline \multirow{2}{*}{ Parameters } & \multirow{2}{*}{ Variation } & \multicolumn{4}{|c|}{ Observed values } \\
\hline & & R.T & T.P & Tailing & Resolution \\
\hline \multirow{2}{*}{ Flow rate } & $0.5 \mathrm{~mL} / \mathrm{min}$ & 3.63 & 5942 & 1.22 & 10.86 \\
\hline & $0.7 \mathrm{~mL} / \mathrm{min}$ & 3.62 & 5910 & 1.19 & 10.23 \\
\hline \multirow{2}{*}{ Column temperature } & $20^{\circ} \mathrm{C}$ & 3.62 & 6308 & 1.25 & 11.22 \\
\hline & $30^{\circ} \mathrm{C}$ & 3.75 & 6115 & 1.22 & 9.79 \\
\hline \multirow{2}{*}{ Mobile phase } & $90 \%$ organic & 3.63 & 5960 & 1.23 & 10.79 \\
\hline & $110 \%$ organic & 3.62 & 5840 & 1.25 & 9.29 \\
\hline
\end{tabular}

TABLE 10: Results of quetiapine fumarate in marketed product.

\begin{tabular}{lccc}
\hline $\begin{array}{l}\text { Marketed } \\
\text { formulation }\end{array}$ & Drug & $\%$ amount obtained & $\%$ RSD \\
\hline Brand 1 & Quetiapine-200 mg & $98.49 \pm 0.36$ & 0.36 \\
Brand 2 & Quetiapine-300 mg & $98.59 \pm 0.34$ & 0.35 \\
\hline
\end{tabular}

Each value is a result of triplicate analysis.

\section{Results and Discussions}

3.1. Method Development and Validation. The HPLC procedure was optimized with a view to develop a stability indicating assay method. Different permutations and combinations, at different $\mathrm{pH}$ values ranging from $\mathrm{pH} 3.0$ to $\mathrm{pH} 11.0$ using various columns like Hypersil-BDS-C18, Symmetry C18, YMC-PACK C18, and YMC-PACK PRO, have been tried with different buffer salts such as ammonium acetate, potassium-di-hydrogen orthophosphate, dipotassium hydrogen orthophosphate, in combination with acetonitrile, methanol, and tetrahydrofuran. However, good resolution, less tailing, and high theoretical plates are obtained with Genesis column C18 $50 \times 4.6 \mathrm{~cm}$. The mobile consists of $50: 50 \mathrm{v} / \mathrm{v}$ acetonitrile and $0.1 \%$ orthophosphoric acid. To the $0.1 \%$ orthophosphoric acid $500 \times 10^{-6} \mathrm{~L}$ of triethyl amine is added for $500 \mathrm{~mL}$ of buffer. The flow rate of the method is $0.6 \mathrm{~mL} / \mathrm{min}$. Diluent is prepared in the same way as mobile phase which consists of $(50: 50)$ methanol and $0.1 \%$ orthophosphoric acid without addition of tri-ethyl amine. The wavelength of detection is $294 \mathrm{~nm}$. The column temperature is maintained at $25^{\circ} \mathrm{C}$. At the reported flow rate peak shape was excellent; however, increasing or decreasing the flow rate increased the tailing factor and resulting in poor peak shape and also resolution between the drug and internal standard also decreased. Hence $0.6 \mathrm{~mL} / \mathrm{min}$ was optimized flow rate decreasing the consumption of the mobile phase, which in turn proves to be cost effective for long-term routine quality control analysis. There was no interference in the drug and internal standard, from the blank. The peak-shape and symmetry were found to be good when the mobile-phase composition of $50: 50 \mathrm{v} / \mathrm{v}$ was used with better resolution of the drug and internal standard.

\subsection{Method Validation}

3.2.1. System Suitability. The \% RSD of the peak area and the retention time for both drug and internal standard are within the acceptable range (Table 1). The efficiency of the column expressed as the number of USP theoretical plates for the six replicate injections was around $5527 \pm 73$ and the USP tailing factor was $1.25 \pm 0.002$ and the USP resolution between the internal standard and drug is $10.31 \pm 0.08$.

3.2.2. Detection and Quantization Limits (Sensitivity). Figures 2 and 3 represent the six replicate injections of the limit of detection and limit of quantification. The method is found to be sensitive which can be determined from the data obtained from Tables 2 and 3 . The LOD concentration is $0.1 \times 10^{-3} \mathrm{~g} / \mathrm{Lt}$. The LOQ concentration is $0.2 \times 10^{-3} \mathrm{~g} / \mathrm{Lt}$.

3.2.3. Linearity. The calibration curve constructed was evaluated by its correlation coefficient. The peak area ratio of the drug and internal standard was linear, and the range is 2.01 and $50.20 \mu \mathrm{g} / \mathrm{mL}$. The linearity was determined in three sets; the correlation coefficient $\left(R^{2}\right)$ was consistently greater then 0.999 (Table 4). From the data in Figure 4 and Table 4 regression equation, limit of quantification, and limit of detection were determined from the calibration curve method:

regression equation: $y=25.10 x-1.186$. 
TABLE 11: Comparison study of various methods with present analytical work.

\begin{tabular}{|c|c|c|c|c|}
\hline $\begin{array}{l}\text { Reference } \\
\text { number }\end{array}$ & Detector & $\begin{array}{l}\text { Type of } \\
\text { analysis }\end{array}$ & Column & Other details \\
\hline [8] & HPLC-UV & $\begin{array}{l}\text { Internal } \\
\text { standard }\end{array}$ & $\mathrm{C} 8(150 \times 4.6 \mathrm{~mm} 5 \mu \mathrm{m})$ & $\begin{array}{l}\text { Range: } 4-400 \mathrm{ng} \mathrm{mL}^{-1} \text {; triprolidine was } \\
\text { used as the internal standard. Solid-phase } \\
\text { extraction }\end{array}$ \\
\hline [9] & HPLC-UV & $\begin{array}{c}\text { Related } \\
\text { impurities }\end{array}$ & Agilent XDB-C18, $50 \times 4.6 \mathrm{~mm}$ & $\begin{array}{l}\text { Range: LOQ to } 150 \% \text { of test } \\
\text { concentration. }\end{array}$ \\
\hline [16] & $\begin{array}{c}\text { LC- } \\
\text { MS/MS }\end{array}$ & NA & $\begin{array}{c}\text { Luna } \mathrm{C}_{18} \text { columns }(50 \mathrm{~mm} \times 2.0 \mathrm{~mm} \text {, } \\
5 \mu \mathrm{m})\end{array}$ & $\begin{array}{l}\text { Range: } 0.70-500 \mathrm{ng} / \mathrm{mL} \text { liquid-liquid } \\
\text { extraction technique. }\end{array}$ \\
\hline [19] & $\begin{array}{l}\text { LC-MS- } \\
\text { MS }\end{array}$ & $\begin{array}{l}\text { Internal } \\
\text { standard }\end{array}$ & Oasis-HLB & $\begin{array}{c}\text { Range: } 1.0 \text { to } 382.2 \mathrm{ng} / \mathrm{mL} \text {, solid phase } \\
\text { extraction }\end{array}$ \\
\hline Present study & HPLC-UV & $\begin{array}{l}\text { Internal } \\
\text { Standard }\end{array}$ & Genesis-Grace C18, $50 \times 4.6,3 \mu \mathrm{m}$ & Range: 2.01 to $50 \mu \mathrm{m} / \mathrm{mL}$ \\
\hline
\end{tabular}

3.2.4. Accuracy and Precision. Accuracy and precision calculated for the QC samples during the intra- and interday run are given in Table 5. The intraday (day 1) and interday accuracy ranged from 98.61 to 101.97 . The results obtained from intermediate precision (interday) also indicated a good method precision. All the data were within the acceptance criteria.

3.2.5. Specificity. Specificity was determined from blank (Figure 5), zero blank (Figure 6), and sample containing both internal standard and drug (Figure 7).

3.2.6. Stability. Stability studies were done for short-term stability up to $12 \mathrm{hrs}$, autosampler stability up to $24 \mathrm{hrs}$, and long-term stability up to 30 days at three different concentrations of low QC, medium QC, and high QC levels conditions and the mobile phase is stable up to $72 \mathrm{hrs}$ (Table 6).

3.2.7. Stress Testing. The stress studies involved heat, acid, light (UV), oxidation, and alkaline conditions. The drug is reasonably stable in all these conditions and no significant degradation is observed. In certain conditions such alkaline conditions certain degraded peaks were observed accompanied with a reduction in the number of theoretical plates and increasing tailing and all these peaks were well resolved from drug and internal standard peaks (Tables 7 and 8). All these experimental and stress conditions were within the range of $90-110 \%$ for all stress conditions indicating the stability of the analytical method. The drug peaks obtained from all stress conditions were found to be homogeneous and pure. Hence this method is specific.

3.3. Robustness Study. Robustness is the measure of method capacity to remain unaffected by deliberate small changes in the chromatographic conditions. The experimental conditions were deliberately altered to test evaluate the robustness of the method. The impact of flow rate $(0.6 \pm 0.1)$, column temperature $\left(25^{\circ} \mathrm{C} \pm 5^{\circ} \mathrm{C}\right)$ changes, and effect of mobile-phase composition $( \pm 10 \%)$ was evaluated on the important system suitability factors such as retention time, theoretical plates, tailing factor, and resolution were studied. The experimental results were presented in Table 9.

3.4. Application of the Method to Dosage Forms. The HPLC method developed is sensitive and specific for the quantitative determination of quetiapine fumarate. Also the method is validated for different parameters, hence has been applied for the estimation of drug in pharmaceutical dosage forms. Quetiapine fumarate tablets of $200 \mathrm{mg}$ and $300 \mathrm{mg}$ strength from two different manufacturers were evaluated for the amount of quetiapine fumarate. The amount of quetiapine fumarate in tablet 1 is $98.49 \pm 0.36$ and tablet 2 is 98.59 \pm 0.35 (Table 10). None of the tablets ingredients interfere with the analytic peak. The spectrum of quetiapine fumarate extracted from the tablets was matching with that of standard quetiapine fumarate showing the purity of peak of quetiapine fumarate in the tablets.

\section{Conclusion}

A rapid sensitive and specific method for the determination of quetiapine fumarate in the pharmaceutical formulations has been developed using lamotrogine as the internal standard. The method gave accurate and precise results in the concentration range from 2.01 to $49.500 \times 10^{-3} \mathrm{~g} / \mathrm{Lt}$. The mobile-phase composition is $50: 50$ acetonitrile: $0.1 \%$ orthophosphoric acid, at the flow rate of $0.6 \mathrm{~mL} / \mathrm{min}$. The retention times of internal standard and the drug are 1.45 \pm 0.05 and $3.6 \pm 0.05$, respectively. The column is a $50 \times$ $4.6 \mathrm{~mm} \mathrm{C18}$ column with the particle size of $3 \mu \mathrm{m}$. Quetiapine fumarate is tested for the stress conditions like photostability, acid stability, alkaline, oxidation, and thermal conditions for the 24 Hrs. Quetiapine fumarate is stable and did not show any signs of degradation under stress conditions.

\section{Abbreviations}

Rs: $\quad$ USP resolution

$T_{1}, T_{1}$ : Retention time of the peak 1 , and peak 2

$W_{1}, W_{2}$ : Peak width 1 and 2 at the baseline 
$T_{R}$ : Retention time along the baseline from the point of injection to the perpendicular dropped from the maximum of the peak corresponding to the analyte

$W_{R}$ : Width of the peak at half the height

$W_{0.5}$ : Width of the peak at $1 / 20$ of peak height

$d$ : Distance between perpendicular dropped from peak maximum to the leading edge of the peak at $1 / 20$ of peak height.

\section{References}

[1] S. B. Bagade, S. P. Narkhede, D. S. Nikam, and C. K. Sachde, "Development and validation of UV-Spectrophotometric method for determination of Quetiapine fumarate in two different dose tablets," International Journal of ChemTech Research, vol. 1, no. 4, pp. 898-904, 2009.

[2] K. Basavaiah, N. Rajendra Prasad, P. J. Ramesh, and K. B. Vinay, "Sensitive ultraviolet spectrophotometric determination of quetiapine fumarate in pharmaceuticals," Thai Journal of Pharmaceutical Sciences, vol. 34, pp. 146-154, 2010.

[3] V. G. Prasanth, S. C. Eapan, S. V. Kutti, and T. S. Jyothi, "Development and validation of Quetiapine fumarate in pure and pharmaceutical formulation by UV-Spectrophotometric method," Der Pharmacia Sinica, vol. 2, no. 6, pp. 52-58, 2011.

[4] K. Basavaiah, N. Rajendra Prasad, P. J. Ramesh, and K. B. Vinay, "Sensitive and selective extraction-free spectrophotometric determination of quetiapine fumarate in pharmaceuticals using two sulphonthalein dyes," Journal of Pre-Clinical and Chemical Research, vol. 4, no. 1, pp. 024-031, 2010.

[5] S. R. Dhaneshwar, N. G. Patre, and M. V. Mahadik, "Stabilityindicating HPTLC method for quantitation of quetiapine fumarate in the pharmaceutical dosage form," Acta Chromatographica, vol. 21, no. 1, pp. 83-93, 2009.

[6] S. Hillaert, L. Snoeck, and W. Van den Bossche, "Optimization and validation of a capillary zone electrophoretic method for the simultaneous analysis of four atypical antipsychotics," Journal of Chromatography A, vol. 1033, no. 2, pp. 357-362, 2004.

[7] S. A. Ozkan, B. Dogan, and B. Uslu, "Voltammetric analysis of the novel atypical antipsychotic drug quetiapine in human serum and urine," Microchimica Acta, vol. 153, no. 1-2, pp. 27-35, 2006.

[8] R. Mandrioli, S. Fanali, A. Ferranti, and M. A. Raggi, "HPLC analysis of the novel antipsychotic drug quetiapine in human plasma," Journal of Pharmaceutical and Biomedical Analysis, vol. 30, no. 4, pp. 969-977, 2002.

[9] I. V. Somaraju, P. Raghuram, and J. Sriramulu, Chromatographia, vol. 70, no. 3, pp. 4545-4550, 2009.

[10] M. A. Saracino, L. Mercolini, G. Flotta, L. J. Albers, R. Merli, and M. A. Raggi, "Simultaneous determination of fluvoxamine isomers and quetiapine in human plasma by means of highperformance liquid chromatography," Journal of Chromatography B, vol. 843, no. 2, pp. 227-233, 2006.

[11] L. Mercolini, M. Grillo, C. Bartoletti, G. Boncompagni, and M. A. Raggi, "Simultaneous analysis of classical neuroleptics, atypical antipsychotics and their metabolites in human plasma," Analytical and Bioanalytical Chemistry, vol. 388, no. 1, pp. 235-243, 2007.

[12] J. Hasselstrøm and K. Linnet, "Fully automated on-line quantification of quetiapine in human serum by solid phase extraction and liquid chromatography," Journal of Chromatography B, vol. 798, no. 1, pp. 9-16, 2003.
[13] K.-Y Li, Y.-G Zhou, H.-Y Ren, F. Wang, B.-K Zhang, and H.$\mathrm{D} \mathrm{Li}$, "Ultra-performance liquid chromatography-tandem mass spectrometry for the determination of atypical antipsychotics and some metabolites in in vitro samples," Journal of Chromatography B, vol. 850, no. 1-2, pp. 581-585, 2007.

[14] J. Sachse, J. Köller, S. Härtter, and C. Hiemke, "Automated analysis of quetiapine and other antipsychotic drugs in human blood by high performance-liquid chromatography with column-switching and spectrophotometric detection," Journal of Chromatography B, vol. 830, no. 2, pp. 342-348, 2006.

[15] R. H. Pullen, K. M. Palermo, and M. A. Curtis, "Determination of an antipsychotic agent (ICI 204,636) and its 7-hydroxy metabolite in human plasma by high-performance liquid chromatography and gas chromatography-mass spectrometry," Journal of chromatography, vol. 573, no. 1, pp. 49-57, 1992.

[16] P. C. Davis, O. Bravo, M. Gehrke, and C. T. Azumaya, "Development and validation of an LC-MS/MS method for the determination of quetiapine and four related metabolites in human plasma," Journal of Pharmaceutical and Biomedical Analysis, vol. 51, no. 5, pp. 1113-1119, 2010.

[17] Z. Zhou, X. Li, K. Li et al., "Simultaneous determination of clozapine, olanzapine, risperidone and quetiapine in plasma by high-performance liquid chromatography-electrospray ionization mass spectrometry," Journal of Chromatography B, vol. 802, no. 2, pp. 257-262, 2004.

[18] H. Kirchherr and W. N. Kühn-Velten, "Quantitative determination of forty-eight antidepressants and antipsychotics in human serum by HPLC tandem mass spectrometry: a multilevel, single-sample approach," Journal of Chromatography $B$, vol. 843, no. 1, pp. 100-113, 2006.

[19] B. Barrett, M. Holcapek, J. Huclová et al., "Validated HPLCMS/MS method for determination of quetiapine in human plasma," Journal of Pharmaceutical and Biomedical Analysis, vol. 44, no. 2, pp. 498-505, 2007. 

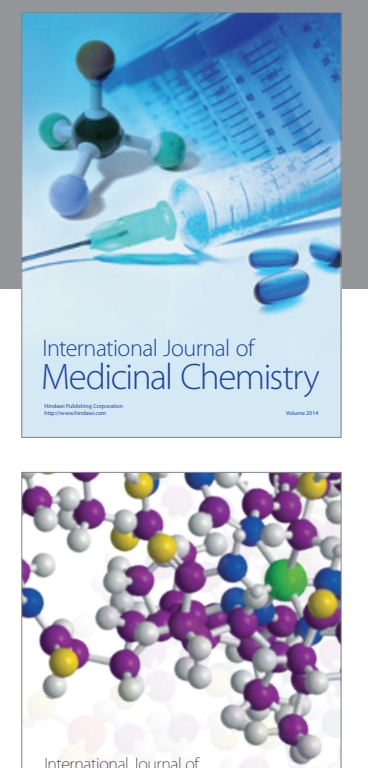

\section{Carbohydrate} Chemistry

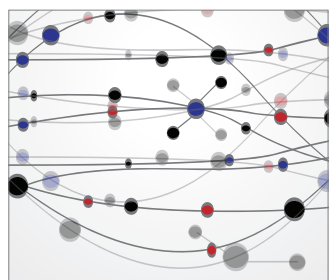

The Scientific World Journal
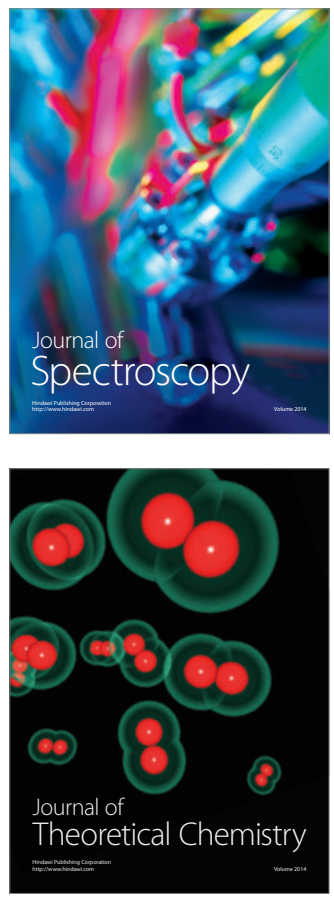
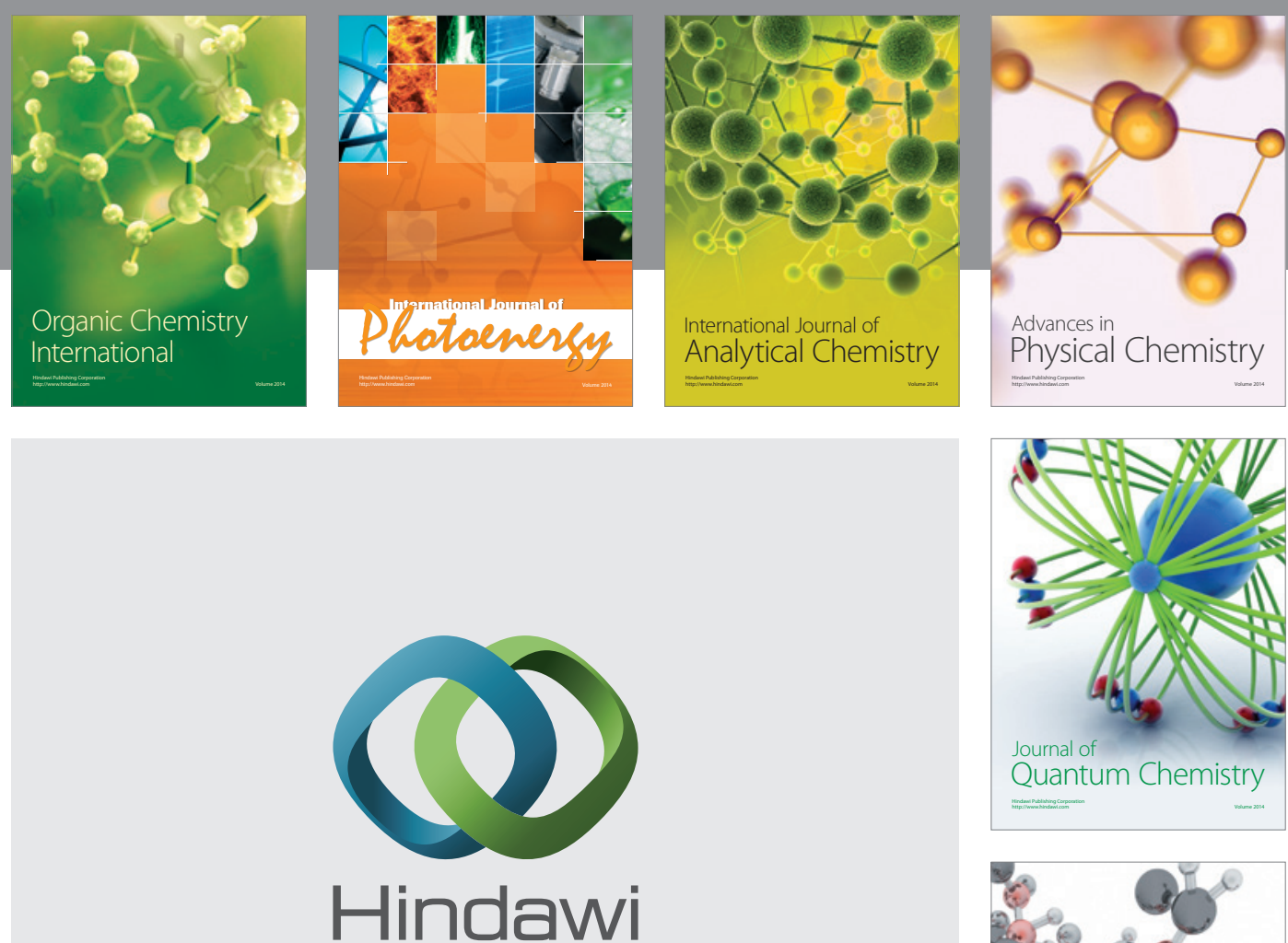

Submit your manuscripts at

http://www.hindawi.com

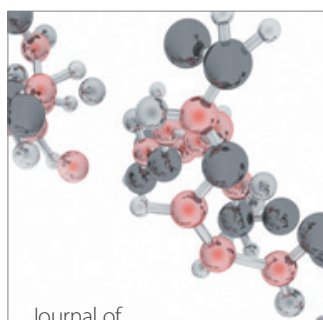

Analytical Methods

in Chemistry

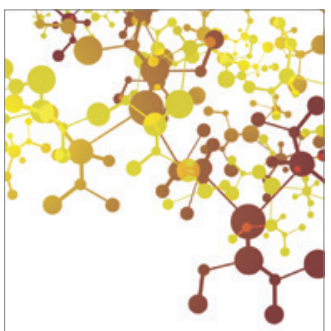

Journal of

Applied Chemistry

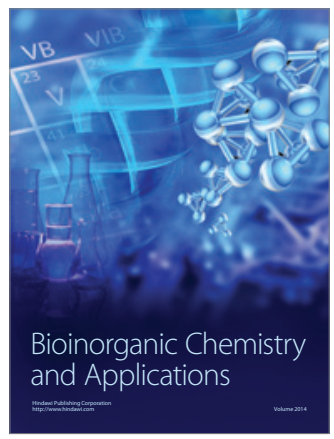

Inorganic Chemistry
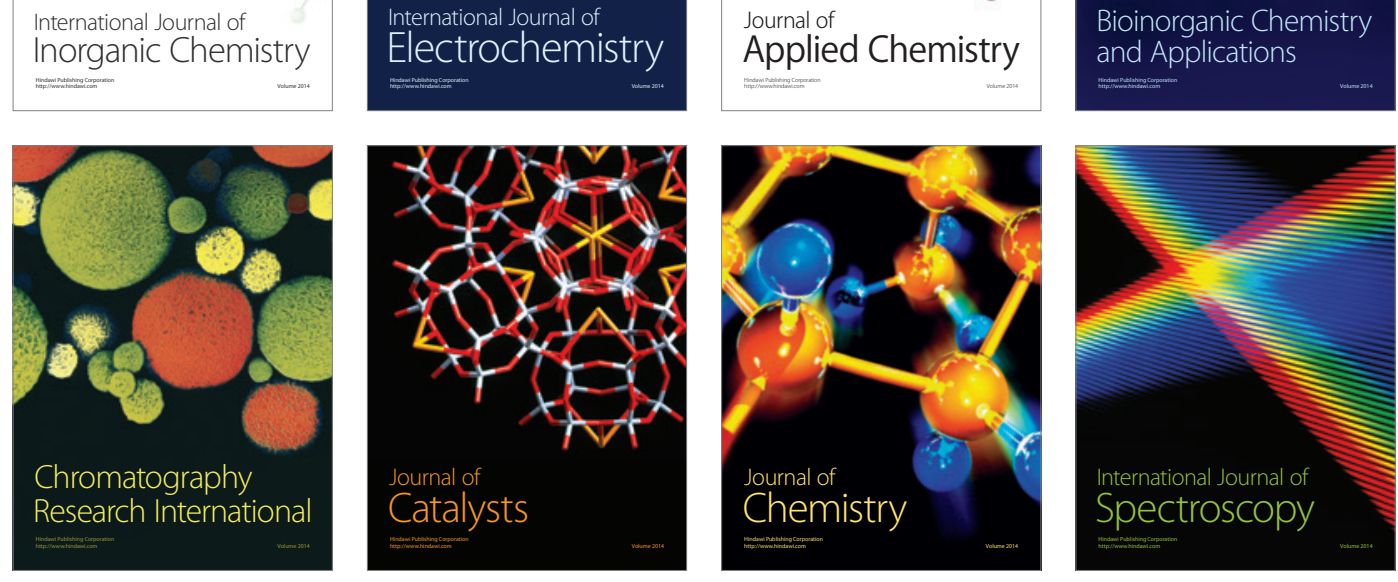